\title{
Ressignificação dos saberes e prática- O ensino da Saúde Mental na graduação de Enfermagem
}

\author{
Ressignification of knowledge and practice- Teaching Mental Health in Nursing graduation \\ Resignificación del conocimiento y la práctica - Enseñanza en Salud Mental en la graduación de \\ Enfermería
}

\author{
Jaksiana Batista da Silva \\ ORCID: https://orcid.org/0000-0001-7190-8516 \\ Universidade Federal de Juiz de Fora, Brasil \\ E-mail: jaksiana@hotmail.com \\ Fabíola Lisboa da Silveira Fortes \\ ORCID: https://orcid.org/0000 -0002-3072-8452 \\ Universidade Federal de Juiz de Fora, Brasil \\ E-mail: fabylisboa@bol.com.br \\ Andyara do Carmo Pinto Coelho Paiva \\ ORCID: https://orcid.org/0000-0002-3567-8466 \\ Universidade Federal de Juiz de Fora, Brasil \\ E-mail: luandyjf@yahoo.com.br \\ Darla Tormen \\ ORCID: https://orcid.org/0000-0001-5203-1042 \\ Universidade Federal de Juiz de Fora, Brasil \\ E-mail: darlatormen@yahoo.com.br
}

\begin{abstract}
Resumo
O objetivo deste estudo é compreender a forma de atuação do profissional enfermeiro no campo da saúde mental no período pós Reforma Psiquiátrica, tendo como subsídio a sua formação durante a graduação. Trata-se de uma pesquisa qualitativa, com características descritiva e exploratória, baseada em uma pesquisa de campo, onde foram entrevistados 8 profissionais enfermeiros atuantes nos Centros de Atenção Psicossocial (CAPS) do município de Juiz de Fora - MG e administrados exclusivamente pela prefeitura da cidade. Resultados: surgiram dois tópicos: Reflexo da formação no campo de atuação e Necessidade de atualização dos atos profissionais na saúde mental, onde podemos constatar que a formação durante a graduação no que tange a saúde mental foi incipiente, com conteúdo teóricoprático desarticulado e descontextualizado do cotidiano dos serviços substitutivos. Todos confirmaram que exploraram outros materiais e fontes para se aperfeiçoar e compreender melhor os assuntos pertinentes ao cuidado em saúde mental ao decorrer da sua atuação no CAPS. Conclusão: Evidenciado na pesquisa que mesmo após 20 anos da Lei 10.216, os enfermeiros continuam com dificuldades para reconhecer sua práxis dentro dos CAPS e reconhecem que os conteúdos adquiridos durante a sua formação não foram suficientes para um trabalho adequado dentro dos moldes da nova ideologia da saúde mental.
\end{abstract}

Palavras-chave: Enfermagem psiquiátrica; Assistência à saúde mental; Cuidados de enfermagem; Ensino.

\begin{abstract}
The objective of this study is to understand the way in which the professional nurse works in the field of mental health in the post-Psychiatric Reform period, having as a subsidy their training during graduation. It is a qualitative research, with descriptive and exploratory characteristics, based on a field research, in which 8 professional nurses working at the Psychosocial Care Centers (CAPS) of the city of Juiz de Fora - MG were interviewed and administered exclusively by the city hall. Results: two topics emerged: Reflection of training in the field of action and Need to update professional acts in mental health, where we can see that training during undergraduate courses regarding mental health was incipient, with theoretical and practical content that was disjointed and decontextualized substitute services. All confirmed that they explored other materials and sources to improve and better understand the issues pertinent to mental health care during their work at CAPS. Conclusion: It was evidenced in the research that even after 20 years of Law 10.216, nurses continue to have difficulties in recognizing their praxis within the CAPS and recognize that the contents acquired during their training were not sufficient for an adequate work within the framework of the new ideology of mental health.
\end{abstract}

Keywords: Psychiatric nursing; Mental health assistance; Nursing care; Teaching. 


\begin{abstract}
Resumen
El objetivo de este estudio es comprender la forma en que trabaja el profesional de enfermería en el campo de la salud mental en el período post Reforma Psiquiátrica, teniendo como subsidio su formación durante la graduación. Se trata de una investigación cualitativa, con características descriptivas y exploratorias, basada en una investigación de campo, donde 8 enfermeras profesionales que laboran en los Centros de Atención Psicosocial (CAPS) de la ciudad de Juiz de Fora - MG fueron entrevistadas y administradas exclusivamente por la alcaldía de la ciudad de Juiz de ForaMG. Resultados: surgieron dos temas: Reflexión de la formación en el campo de acción y Necesidad de actualización de los actos profesionales en salud mental, donde se observa que la formación durante los cursos de pregrado en materia de salud mental era incipiente, con contenidos teóricos y prácticos desarticulados y descontextualizados servicios sustitutos. Todos confirmaron que exploraron otros materiales y fuentes para mejorar y comprender mejor los problemas pertinentes a la atención de la salud mental durante su trabajo en CAPS. Conclusión: Se evidenció en la investigación que aún después de 20 años de la Ley 10.216, los enfermeros continúan teniendo dificultades para reconocer su praxis dentro del CAPS y reconocen que los contenidos adquiridos durante su formación no fueron suficientes para un adecuado trabajo en el marco de la nueva ideología de la salud mental.
\end{abstract}

Palabras clave: Enfermería psiquiátrica; Atención a la salud mental; Atención de enfermería; Enseñanza.

\title{
1. Introduçãa
}

A instituição dos hospitais psiquiátricos como local de tratamento para a loucura na sociedade ocidental iniciou-se ainda no século XVIII com Philippe Pinel, médico francês psiquiatra, que definiu pela primeira vez a loucura como um distúrbio mental e por se tratar de uma doença, necessita de tratamento para tal. Nesta perspectiva, Pinel estabelece uma nova abordagem de tratamento para estes indivíduos, afirmando que a loucura é um desvio passional dependente das percepções e sensações do indivíduo para se manifestar. O isolamento desses sujeitos, os afastando de todas as influências do meio e de seus familiares foi visto pelo médico como a forma de tratamento para estes indivíduos, algo que perdurou até meados do século XX (Coelho et al., 2014; Teixeira, 2019).

Na década de 70, inicia-se o movimento da Reforma psiquiátrica (RP), que traz para a luz a discussão do quão prejudicial e adoecedor é o modelo da psiquiatria tradicional e a necessidade de superá-lo por um novo modelo de saúde mental biopsicossocial, com implantação de novas formas de cuidar humanizadas e inclusivas. $\mathrm{O}$ processo de desinstitucionalização, apresentado por este movimento, caracteriza-se pela reintegração destes indivíduos que por anos foram esquecidos dentro dos asilos/manicômios na sociedade e não se resume em apenas na retirada destes sujeitos de dentro destas instituições, mas problematiza a forma com que a sociedade lida com a loucura, e a prepara para compreender a complexidade deste fenômeno, restaurando a cidadania destes sujeitos e devolvendo a sua identidade (Vargas et al., 2018).

A assistência da enfermagem no campo da psiquiatria foi construída e desenvolvida dentro dos hospitais psiquiátricos. Sob o controle do saber hegemônico do médico, as intervenções de enfermagem neste campo por muitos anos foram reduzidas a medidas coercitivas e de vigilância, onde a enfermagem assume como principal tarefa aplicar as condutas para reprimir e manter a ordem dos pacientes (Esperidião et al., 2013; Muniz et al., 2015).

Com a transição para o novo modelo "extramuros", o trabalho do enfermeiro, antes totalmente pautado na perspectiva médico-centrada, necessita se readaptar e ressignificar seus saberes e práticas, centralizando nos aspectos subjetivos do sujeito. A nova conjuntura, requer atualização das intervenções terapêuticas que contemplam as verdadeiras necessidades do indivíduo e romper com condutas da antiga assistência, que estabelecia o isolamento social e a hipermedicalização. Torna-se, portanto, importante para a enfermagem a construção do relacionamento terapêutico, uma escuta qualificada, um atendimento individualizado resolutivo, o acolhimento, a criação de vínculos e um trabalho com a comunidade junto com a equipe intersetorial e multidisciplinar (Maftum et al., 2017).

Com a nova assistência, ocorre a implantação da nova Política Nacional em Saúde Mental (PNSM) priorizando o modelo psicossocial, a ampliação dos Centros de Atenção Psicossocial (CAPS) no Brasil e a instituição da Rede de atenção Psicossocial (RAPS), garantindo assim o direito das pessoas em sofrimento psíquico, o cuidado integral, em liberdade, inseridas em seu território e direcionado à sua subjetividade. Os outros pontos de atenção que compõem a RAPS são: A 
Atenção Básica, os hospitais-dia, os serviços de Urgência e Emergência Psiquiátrica, os leitos em hospitais gerais, as Residências Terapêuticas e as Unidades de Acolhimento (Borges et al., 2016; Nunes et al., 2020).

Os CAPS são dispositivos terapêuticos ligados ao Sistema Único de Saúde (SUS), abertos, comunitários, composto por equipe multidisciplinar que realiza um trabalho intersetorial com a finalidade de atender o usuário em todos os níveis de complexidade, com o intuito de proporcionar sua reinserção na sociedade. A assistência prestada ao usuário em sofrimento psíquico inclui: atendimentos individuais para os diversos propósitos, realização de grupos para suporte social, oficinas terapêuticas, visitas domiciliares, atendimento com a família, ações intersetoriais com os diversos setores da sociedade, não apenas com os relacionados a saúde, mas também com os da assistência social, educação, cultura entre outros (Brasil, 2015; Borges et al., 2016).

Frente a isso, o profissional enfermeiro necessita neste novo período desenvolver novas habilidades e competências para atingir o cuidado holístico destes sujeitos, atuando para além das especificidades da profissão, fixando na singularidade do outro, em suas vivências, e por meio da relação interpessoal perceber as características humanas e sociais que compõe aquele indivíduo no meio em que vive e incluí-lo ativamente no seu processo saúde/doença a fim da reabilitação, reinserção e promoção do autocuidado (Esperidião et al., 2013; Tavares et al., 2016).

Considerando as transformações ocorridas no processo de trabalho da enfermagem após a Reforma Psiquiátrica, é essencial que haja uma formação que integre estas novas competências e habilidades. Por este motivo, o presente artigo tem por objetivo compreender a forma de atuação do enfermeiro no campo da Saúde Mental no período pós Reforma Psiquiátrica, tendo como subsídio a sua formação durante a graduação.

A justificativa para o estudo se deve a minha experiência nos serviços de Saúde Mental durante a Residência Multiprofissional, onde vivenciei a grande dificuldade dos profissionais enfermeiros em identificar e compreender o seu papel e relevância dentro do novo contexto de assistência à saúde mental. Haja visto, que as atividades realizadas dentro daquele cenário não compactuam com os conhecimentos adquiridos durante a sua formação, algo que foi observado em todos os Centros de Atenção Psicossocial por onde foi desenvolvido a minha residência.

\section{Metodologia}

Realizou-se uma pesquisa de campo com abordagem qualitativa, descritiva e exploratória no mês de novembro de 2020. A amostra foi composta por enfermeiros atuantes em um dos 4 CAPS da cidade de Juiz de Fora- MG administrados exclusivamente pela prefeitura da cidade.

Adotou-se como critérios de inclusão: ser enfermeiros atuantes nos CAPS, não possuir especialização/pós-graduação em Saúde Mental concluída até a data da entrevista e que concordaram em participar da pesquisa ao receber o Termo de Consentimento Livre e Esclarecido (TCLE). Como critério de exclusão, foram excluídos os profissionais que possuem titulação de especialista em Saúde Mental. O motivo dessa exclusão é devido ao potencial risco de enviesamento no estudo por parte destes profissionais. Ao todo, 10 enfermeiros que atuam em um dos 4 CAPS do município aceitaram participar da pesquisa, sendo que 2 foram excluídos por declararem serem enfermeiros especialistas em Saúde Mental.

A abordagem qualitativa de caráter descritiva e exploratória foi escolhida por se mostrar mais apropriada para a abordagem do estudo. O método qualitativo tem como base o caráter subjetivo, possibilitando o pesquisador compreender como as particularidades e experiências são conceituadas pelo indivíduo. Normalmente neste tipo de metodologia a análise dos dados e das informações levantadas segue o método indutivo e a resposta do problema é obtida por meio da interpretação de textos e números. A pesquisa qualitativa responde a questões muito particulares do sujeito, onde o pesquisador se preocupa com a subjetividade e os significados que o entrevistado impõe sobre o fenômeno de estudo (Minayo, 2002; Câmara, 2013; Pereira et al., 2018). 
Considerando o objetivo do estudo, foi identificado que o método exploratório é adequado ao trabalho, devido a sua característica de familiarização com o problema, possibilitando a maior exposição e compreensão do referido problema (Gil, 2002).

$\mathrm{O}$ estudo respeitou as exigências formais contidas nas normas nacionais e internacionais regulamentadoras de pesquisas envolvendo seres humanos e foi aprovada pelo Comitê de Ética em Pesquisa da Universidade Federal de Juiz de Fora por meio do parecer: 4.371-851.

Devido a pandemia da COVID-19 e a necessidade do distanciamento social para a mitigação dos casos, a entrega do Termo de Consentimento Livre e Esclarecido e do instrumento de coleta de dados não foi realizada de forma presencial e sim através do Formulário Google encaminhado para os participantes por e-mail, garantindo assim a segurança de todos os envolvidos. O instrumento de coleta de dados consistiu de um roteiro de entrevista semiestruturado onde o participante pôde falar livremente sobre o tema abordado. Para garantir o sigilo e a confidencialidade, a identidade dos participantes foi preservada por meio da codificação E1,2020; E2,2020 e assim sucessivamente até o código E8,2020.

$\mathrm{Na}$ análise dos dados foi usado a técnica de análise de conteúdo de Bardin, do tipo análise temática. De acordo com Caregnato e Mutti (2006):

“A análise de conteúdo (AC) é um conjunto de técnicas de análise de comunicação e trabalha com o conteúdo, com a materialidade linguística através das condições empíricas do texto, estabelecendo categorias para sua interpretação. “

É um conjunto de técnicas de pesquisa que possibilita ao pesquisador fazer inferências sobre as informações coletadas no processo de entrevista, através de procedimentos sistemáticos, especializados e científicos e classificar os elementos em categorias identificando o que eles têm em comum, permitindo assim o seu agrupamento (Bardin, 1977; Caregnato \& Mutti, 2006).

Como aporte teórico para refletir a respeito das questões suscitadas neste estudo e estabelecer uma articulação com a sociologia foi utilizado a perspectiva do sociólogo francês Pierre Félix Bourdieu, que em seus textos, desenvolve uma investigação e crítica sociológica sobre várias áreas do conhecimento, tais como: educação, cultura, arte, linguística e política. Alguns dos conceitos que estabelece e afirma que constituem a sociedade são: Poder simbólico, habitus, campo social, capital e violência simbólica e estes são passíveis para desenvolver uma interface a dinâmica de ensino-aprendizagem do enfermeiro possibilitando a construção de uma análise crítica sobre as repercussões destes conceitos na sua atuação quando inserido nos equipamentos biopsicossocial (Bourdieu, 1989; Fortes, 2017).

Em sua obra intitulada "O Poder Simbólico", este autor explana sobre as relações de poder através de estruturas simbólicas que se convertem em instrumentos de poder. Bourdieu traz para a luz da discussão a afirmação de que as relações de poder que é estabelecido na sociedade contemporânea deixaram de prevalecer somente na esfera econômica e material e passou a estar imposta também na forma de Poder Simbólico, sendo revestido por além do capital econômico, mas também com o capital social, cultural e simbólico (Bourdieu, 1989; Lopes, Sobrinho \& Costa, 2013).

O Poder Simbólico, portanto, é definido pelo autor como um "poder invisível”, imperceptível, escondido nas entrelinhas, e exercido com a cumplicidade dos agentes que estão sujeitos a este poder. O habitus, outro conceito abordado por Bourdieu, se assemelha a uma matriz cultural que imprime a noção de identidade para o agente dominado e pode ser compreendido como a materialização de condutas, reações, percepções, estilo de vida e visão do mundo, colocadas como verdadeiras e universais que estes sujeitos são compelidos a reproduzir de forma naturalizada e inconsciente, funcionando como orientação para eles dentro do seu campo social. Bourdieu também identifica na sociedade os campos sociais, que são locais onde os sujeitos realizarão disputas por posições e onde legitimam e normatizam as representações. Por último, a Violência Simbólica citada pelo francês trata-se da imposição e da reprodução do discurso dominante, reconhecido pelos agentes dominados como legítimo (Bourdieu, 1989; Lopes, Sobrinho \& Costa, 2013; Fortes, 2017). 


\section{Resultados e Discussão}

Dos 8 enfermeiros que participaram da pesquisa, apenas um foi egresso de instituição privada enquanto os demais se graduaram em instituições públicas. Os entrevistados foram em sua maioria do sexo feminino, tendo somente um enfermeiro do sexo masculino. A faixa etária variou entre 27 a 42 anos, com tempo de formado de 3 a 20 anos e tempo de atuação no campo da saúde mental entre 4 meses a 7 anos. Todos confirmaram que exploraram outros materiais e fontes para se aperfeiçoar e compreender melhor os assuntos pertinentes ao cuidado em saúde mental ao decorrer da sua atuação no CAPS. Após análise dos dados conseguimos delimitar duas categorias: Reflexo da formação no campo de atuação e Necessidade de atualização dos atos profissionais na saúde mental.

\section{Categoria 1 - Reflexo da formação no campo de atuação}

A categoria em questão trata da autoavaliação dos entrevistados quanto a sua formação, levando em consideração o ensino teórico e prático e a integração entre o que foi transmitido em sala de aula com a execução na prática.

De acordo com os dados coletados, sete enfermeiros trazem em seus discursos que tanto a carga horária conferida a disciplina da saúde mental na graduação quanto o conteúdo destinado a esta temática foi insatisfatório e escasso, com pouca articulação do saber teórico produzido no campo acadêmico com a realidade prática. "Incompleto", "Fraca", "Básica" e "Precária" foram alguns dos adjetivos utilizados pelos depoentes ao descrever sua formação durante a graduação em relação à temática da saúde mental.

“Conhecimento superficial que oferta um panorama geral da psiquiatria. Reflete pouco a realidade” (E3,2020)

"A disciplina foi breve, ministrada durante um periodo da faculdade, aproximadamente por 4 meses, em sua maior parte por mestrandos. Durante a atuação nos CAPS identifico temas e competências, os quais devem aprimorados e mais aprofundados, como: a Rede de Atenção à Saúde Mental e seu fluxo; acolhimento; escuta qualificada; psicotrópicos; Projeto Terapêutico Singular e identificação e possíveis manejos da crise." (E5,2020)

"Na graduação, o tempo destinado à Saúde Mental foi insatisfatório, tanto em si tratando de teoria quanto de prática, impactando de modo a dificultar, inicialmente a atuação como profissional na área. [...] em si tratando especificamente na área da Saúde Mental, não foi suficiente para abarcar um tema de grande relevância para a assistência de Enfermagem. Tive uma escassa prática, principalmente a respeito da temática atenção psicossocial." $(E 7,2020)$

"O tempo foi muito curto, voltado pra leitura de artigos e algumas aulas práticas num caps que eram mais observacionais e não contribuíram muito para o desenvolvimento das habilidades necessárias para se atuar em um caps. “(E8, 2020)

Identifica-se que o ensino da saúde mental na graduação da enfermagem é composto por conteúdos fragmentados, vistos como insuficientes para o trabalho das demandas psicossociais. Observamos pelas falas dos entrevistados que não ocorreu nas instituições de ensino uma preparação que proporcionasse segurança e aptidão para a coordenação e execução das atividades de suporte terapêuticas comuns dos CAPS, como projeto terapêutico singular (PTS), atividades grupais, oficinas terapêuticas, acolhimento e nas intervenções alternativas para a atenção à crise. O conhecimento deficitário a respeito dos objetivos da reforma e de como efetivá-los, gera inseguranças e afeta diretamente a qualidade do atendimento, abrindo precedentes para a reprodução de práticas antiquadas, incapazes de proporcionar um atendimento holístico e humanizado (Carneiro \& Porto, 2014; Borges et al., 2016). 
Percebemos também, além da formação incipiente, a realização de atividades práticas realizadas dentro dos equipamentos substitutivos ao hospital psiquiátrico, porém de forma superficial e desarticulada com que institui o novo paradigma. Um dos entrevistados, conforme a fala abaixo, teve a oportunidade de estagiar dentro de um hospital geral da cidade, todavia, com uma assistência destoante da lógica biopsicossocial e ainda com ênfase em conceitos biomédicos, com enfoque na doença e diagnósticos médicos, sendo desta maneira, contraditório as bases teóricas vista em sala de aula, que era pautado nos princípios da humanização e na Reforma Psiquiátrica.

"Breve e com lacunas. A prática foi em um hospital geral que estava na época com o leito psiquiátrico desativado, $e$ baseava-se em realizar a abordagem e intervenções em pacientes com diagnósticos clínicos. O conteúdo teórico foi através da discussão de artigos e a construção de Portfólio. Era fundamentada no cuidado humanizado e na reforma psiquiátrica". (E5, 2020)

Na nova saúde mental, as práticas devem girar em torno do sujeito e não da sua doença. A formação influenciada pelo modelo biomédico, amparada em aspectos clínicos dificulta a efetivação da integralidade e reforça as condutas medicalizantes, centradas na remissão dos sintomas e na exclusão social. A carência de diálogo entre o conteúdo teórico apresentado em salas de aula com as ações terapêuticas realizadas no cotidiano dos novos serviços contribui para a formação de profissionais limitados, passivos e poucos críticos-reflexivos, principalmente, no que tange ao processo histórico-social e político que culminou com a reforma psiquiátrica e com as novas abordagens de cuidado aos sujeitos em sofrimento psíquico (Borges et al., 2016; Rodrigues et al., 2017).

De acordo com Souza e Silvino (2017) e correlacionando com os conceitos de Bourdieu as instituições de saúde são campos sociais usados para a construção de saberes e desenvolvimento de práticas, sendo espaços hierarquizados onde ocorrem lutas e violência simbólica. O modelo de aprendizagem sustentado na atenção à saúde médico hegemônico, legitima as relações de poder da medicina sob a categoria da enfermagem. Na saúde mental, este Poder Simbólico do médico sob a enfermagem existe desde o período pré-reforma, dentro dos hospitais psiquiátricos, e persiste mesmo com a Reforma Psiquiátrica. A violência simbólica surge como fruto deste poder, de maneira silenciosa e naturalizada, percebida na enfermagem com a supressão da sua autonomia e o afastamento gradativo do seu objeto de trabalho, o sujeito, tornando a cura e o restabelecimento da saúde a centralidade da assistência (Bourdieu, 1989; Duarte et al., 2016; Silva et al., 2017).

Dentre os entrevistados, apenas um profissional descreveu a formação e o tempo destinado ao aperfeiçoamento das novas competências e habilidades para o cuidado em saúde mental como qualificado e satisfatório indo de encontro às propostas da Reforma psiquiátrica.

"Muito boa! Aconteceu de forma prazerosa e estimulava a busca de novos conhecimentos. [...]Entendendo que a graduação tem como foco a formação de enfermeiros generalistas, acredito que o tempo destinado ao conteúdo da saúde mental (prático e teórico) foi o suficiente para desenvolver habilidades e competências básicas e essenciais para a assistência de enfermagem Tive ao longo da graduação professores especialistas e com prática na saúde mental, que possibilitaram compreender o cuidado em saúde mental, nas diversas esferas de atenção á saúde, compreendendo o papel da enfermagem junto a equipe multiprofissional. [...]” $(E 4,2020)$

Conforme Santos et al., (2016), as instituições formadoras precisam fornecer subsídios para que os estudantes possam entender o cuidado em saúde mental em toda as suas esferas, formando profissionais técnicos, conscientes e engajados politicamente, capazes de compreender o processo de adoecimento psíquico e os seus fatores determinantes, além de 
reconhecerem sua função social, comprometidos com o bem-estar do indivíduo e com as necessidades sociais de saúde das pessoas.

Os futuros enfermeiros devem ser preparados para trabalharem na perspectiva biopsicossocial, assumindo uma atitude crítica, questionadora, reflexiva e ao mesmo tempo criativa e inovadora. Devem ter a capacidade de perceber que o cuidado da mente é indissociável de qualquer cuidado prestado ao ser humano e que deve ser estendido em toda ação em saúde praticada em diferentes níveis de atenção, haja visto que uma saúde mental debilitada pode desencadear ou agravar diversas doenças físicas. Espera-se que durante a formação os estudantes sejam capazes de compreender e debater sobre o conceito ampliado de saúde e os seus determinantes sociais. Uma estrutura curricular satisfatória incorpora ações educativas, humanísticas, holísticas, com ênfase nas relações interpessoais e em cuidados primários à saúde mental (Esperidião et al., 2013; Rodrigues et al., 2017; Hertel, 2019).

O não reconhecimento da atuação do enfermeiro na saúde mental assim como o fato da formação não ter proporcionado esta compreensão também foram evidenciadas nos discursos dos entrevistados quando questionados se conseguiam identificar o papel do enfermeiro dentro da Saúde Mental.

[...] A parte teórica foi muito superficial e durante as aulas práticas pouco sabíamos de fluxogramas de atendimento e o papel do enfermeiro na saúde mental, não acompanhávamos o enfermeiro dentro dessas instituições e pouco era notada a presença do acadêmico no serviço." (E2,2020)

"Não muito ainda. Nossa formação é totalmente voltada pra clínica assistencialista e a saúde mental é muito sutil mais voltada para atuação pelo vínculo e pela palavra, ainda é um desafio pra mim”. Não, pelo contrário considero que dificulta ainda mais pois na saúde mental a lógica assistencial é totalmente diferente do que aprendemos na faculdade. "(E8,2020)

Como aponta Souza e Afonso (2015) a desarticulação do eixo teórico-prático e a organização das práticas pedagógicas relacionando a maioria das ações de saúde a assistência clínica-hospitalar induz o enfermeiro a pensar que o seu trabalho no processo de geração de saúde está relacionado apenas à prática hospitalar e habilidades técnicas. Portanto, quando inserido dentro de um campo extra-hospitalar que exige práticas distintas do hospital, surge o fenômeno de perda da identidade profissional. Ao decorrer dos anos a profissão questionou esta prática tradicional e se mobilizou para se consolidar em uma base científica, em busca de maior autonomia e ampliando suas possibilidades de produzir cuidado, todavia, o que percebemos no cotidiano é este paradoxo entre a teoria e a prática e a naturalização inconsciente de que a identidade profissional está interligada a saberes e atos tradicionais (Souza \& Afonso, 2015; Hertel, 2019).

Frente a isso, na Atenção Psicossocial, observa-se que as práticas terapêuticas da enfermagem não devem ser reduzidas a planos e procedimentos prescritos, roteirizados e intervenções protocolizadas. Elas devem incorporar dimensões que possibilitam transformar e qualificar as condições e modos de vida dos usuários. A comunicação terapêutica deve ser aprimorada e precisa ser utilizada para a identificação e o atendimento das reais necessidades do usuário e de suas vulnerabilidades. A escuta qualificada é outra habilidade que deve ser incluída na atenção psicossocial, dando voz a estas pessoas e levando em consideração suas visões e concepções. O profissional necessita compreender que existem diversas formas de reagir e perceber a vida e não procurar enquadrar estas pessoas no chamado comportamento "normal" instituído pela sociedade contemporânea, e sim agir com sensibilidade e empatia, respeitando as limitações de cada um e atuando como um facilitador para que estas pessoas consigam retomar com suas atividades da vida diária e seu exercício de cidadão (Fortes, 2017; Hertel, 2019, Bossato et al., 2020). 
Seguindo a perspectiva de Bourdieu (1989), o habitus direciona os sujeitos que o incorporam a se comportarem de uma determinada forma quando inserido em um contexto. Portanto, a matriz cultural do enfermeiro modelada pelas instituições de ensino findada em uma formação e prática tecnicista o compele a reproduzir estas ações em diferentes cenários e situações. Para a nova assistência instituída na saúde mental, é necessário que o profissional agregue condutas inovadoras que visam o estreitamento das relações sociais, o que implica em uma revisão e transformação do seu habitus, para um trabalho capaz de atingir toda a complexidade que este campo exige (Lopes, Sobrinho \& Costa, 2013; Souza \& Silvino, 2017).

Corroborando que o habitus pode ser mutável, mesmo com as contrariedades presentes no ensino, alguns enfermeiros afirmaram ser capazes de identificar a sua função dentro dos novos equipamentos da rede assistencial, conforme trechos abaixo:

"[..] O enfermeiro tem papel de acolher o usuário e família em sua integralidade, promover ações terapêuticas de promoção, prevenção e reabilitação do usuário, assim como participar da discussão de casos e da articulação da rede. Além disso, desenvolve o papel de ajudar no resgate da autonomia do usuário, garantir direitos de cidadania, promover o autocuidado em todos os seus aspectos, administrar e controlar medicamentos e ofertar esclarecimentos sobre o processo de saúde-adoecimento-cuidado." (E4,2020)

"Considero o enfermeiro como profissional fundamental na equipe multiprofissional. O seu olhar soma e favorece para um cuidado integralizado. O enfermeiro pode atuar através das oficinas, acolhimentos, atendimento individual e familiar promovendo a saúde e o autocuidado; e através da subjetividade traçar projetos para o tratamento do sujeito." (E5,2020)

"Sim. O papel está ligado ao cuidado em todas as dimensões. Ademais as tecnologias leves (relacional) está mais evidentes na atuação do Enfermeiro nessa modalidade." (E6,2020)

"Sim. Somos profissionais com um papel importante no cuidado integral do usuário com transtorno mental. No CAPS estamos inseridos em uma equipe multiprofissional, na qual podemos participar da gestão dos casos, elaboração do Projeto Terapêutico Singular e também realizar o Processo de Enfermagem, por meio da consulta de Enfermagem em Saúde Mental, possibilitando a implementação da Sistematização da Assistência de Enfermagem. “(E7,2020)

Destaca-se nestas falas, que os entrevistados compreendem que o processo de trabalho na atenção psicossocial requer ações terapêuticas que coadunam com as propostas da Reforma Psiquiátrica. O trabalho multiprofissional, intersetorial, com a utilização de tecnologias de cuidado leve (as das relações) para a construção e fortalecimento do relacionamento interpessoal foram valorizados pelos trabalhadores e corrobora o estudo de Cortes et al., (2014) que evidencia que a nova forma de cuidar na saúde mental é atrelada a diversas tecnologias de cuidado e inclusão, tais como: acolhimento, comunicação terapêutica, criação de vínculos, escuta qualificada e acompanhamento do sujeito e de sua família.

Identifica-se nos discursos acima de que foi possível a coexistência de condutas consideradas exclusivas ao enfermeiro, como a Sistematização da Assistência de Enfermagem (SAE) com as especificidades do serviço substitutivo, evidenciando que o campo da saúde mental amplia as ações desta categoria. A SAE permite a sistematização do cuidado e por se tratar de uma ação privativa do enfermeiro, fortalece a noção de identidade profissional. Trata-se de um instrumento que aumenta a autonomia do enfermeiro, possibilitando o planejamento e implementação do cuidado de forma mais independente e resolutiva. Ela operacionaliza e direciona a assistência, objetivando melhorar a qualidade de vida das pessoas, aproximando o profissional do usuário e da equipe multiprofissional e desvincula a atenção apenas dos aspectos biológicos, por meio de ações 
horizontais e coletivas que destacam as singularidades, expandem as potencialidades, e possibilita a (re)construção da identidade e cidadania destes indivíduos (Esperidião et al., 2013; Luz et al., 2014; Souza \& Afonso, 2015).

Observa-se pelas falas que o campo da saúde mental apresentou para a enfermagem novas possibilidades de trabalho que complementam as práticas já adeptas pela profissão em outros cenários, com ações de cunho administrativo, assistencial e educacional. Entre as atividades desempenhadas pelo enfermeiro estão: Supervisão da equipe de enfermagem, elaboração de escalas dos membros desta equipe, dispensação e controle de medicamentos, participação em discussões interdisciplinares, coordenação e participação em atividades grupais. Acolhimento, aconselhamento, visitas domiciliares, orientações a respeito do autocuidado, escuta e orientações aos familiares, processo de enfermagem etc (Borges et al., 2016).

Contudo na fala de um participante, percebemos a dificuldade em aceitar a atividade como técnico em saúde mental, também conhecido como técnico de referência, termo comum dentro dos Centros de Atenção Psicossocial.

\begin{abstract}
"Apresento dificuldade. Muito se fala em técnico em saúde mental, mas minha forma de perceber meu trabalho seria: sou enfermeira, destinando os cuidados de enfermagem em saúde mental e não uma técnica em saúde mental. Nos Caps existem muitos termos que aо meи ver são irrelevantes e acabam prejudicando trabalhar as diversas especificidades de cada profissional nos Caps, isso generalizada as profissões, acho uma perda. "Todos fazem tudo".
\end{abstract} $(E 2,2020)$

Observa-se nesse discurso que o participante não consegue perceber sua atuação como enfermeiro quando assume o posto de técnico de referência e acredita que este conceito ocasiona uma indefinição de funções e a desvalorização das profissões.

O técnico de referência é visto como aquele profissional que faz a interlocução e estreitamento do serviço com o usuário. Possui responsabilidade de monitoramento do sujeito, construir e sustentar o vínculo, acompanhar o progresso do plano terapêutico singular, realizar o contato com a família e a avaliação das metas traçadas no projeto. Conforme autores, esta atividade requer a junção de saberes e campos diversificados, fazendo com que os profissionais abarquem demandas burocráticas, gerenciais e assistenciais que, às vezes, extrapolam os atos adquiridos na graduação. Contudo, estas novas atribuições não transpõem as particularidades da formação, e constitui como algo inovador no cuidado à saúde mental, sendo que para sua execução é preciso a desconstrução das barreiras criadas pela formação tradicional e investir em capacitações e estratégias especializadas para este novo campo (Silva \& Costa, 2010; Souza \& Afonso, 2015).

Lima e Passos (2019) afirmam que o Técnico de Referência nos Centros de Atenção Psicossocial tem a importante função de organizar o processo de trabalho, tornando possível assim, que todos, independentemente da profissão, assumam responsabilidades iguais, seja qual for a necessidade que o usuário apresenta. Desta forma, segundo os autores, é possível realizar um trabalho sem o risco de institucionalizar aquele indivíduo e ainda livrar o campo de lutas simbólicas corporativas entre as categorias profissionais.

Ainda no discurso deste mesmo entrevistado, ele critica a forma como é planejado e gerenciado a disciplina de saúde mental e traz à tona a problemática do desinteresse que esta temática causa nos futuros enfermeiros.

"Na saúde mental assim como diversos outros conteúdos, são trabalhados rapidamente. Considero o tempo destinado ao conteúdo importante sim, mas mais do que isso, pra mim o mais importante seria como é aproveitado o tempo para cada disciplina, se aproveitado de forma significativa muito contribuiria para futuras especializações na área e o que temos hoje é repulsa e desinteresse, justamente pela forma que foi planejada na graduação a apresentação da disciplina." (E2,2020) 
Segundo Baião e Marcolam (2020), há diversos fatores que fazem com que a formação generalista do enfermeiro não contemple todo contexto da saúde mental em todos os ciclos da vida e níveis de atenção. Desde a estrutura curricular com a pouca carga horária disponibilizada, bases teóricas voltadas para estudos de psicopatologias e medicalização, aulas práticas descontextualizadas da realidade dos campos pertencentes a RAPS e falta de docentes capacitados para lecionar o conteúdo desta área o que acarreta na desvalorização do campo.

Sob a ótica de Bourdieu é possível justificar esta concepção distorcida do enfermeiro quando é inserido em um serviço psicossocial devido à ausência do que este autor denomina de capitais (cultural, social e simbólico) acumulados neste campo. Os capitais são elementos que os sujeitos acumulam ao longo da vida e de acordo com o sociólogo não está associado apenas a bens materiais. O capital cultural é definido como o conjunto de conhecimento intelectual do sujeito, atestado por meio de acúmulos de qualificações e diplomas. Já o capital social refere-se às relações sociais privilegiadas e a influência que o indivíduo possui na sua rede de convivência e em suas redes sociais, por último, o capital simbólico está vinculado ao prestígio e honra que a pessoa estabelece na sociedade, não sendo conferido por meio de dinheiro ou títulos, mas sim fruto de qualquer espécie de capital. A história da enfermagem é marcada pelo processo de aprendizado consolidado em dimensões teóricas e práticas clínicas/hospitalares e por esta razão o hospital se tornou o campo onde o profissional investe na aquisição, acúmulo e incorporação de capitais, conferindo-lhe reconhecimento e prestígio e, portanto, o cenário de trabalho que desperta maior interesse para esta profissão (Bourdieu, 1989; Lopes, Sobrinho \& Costa,2013; Neves \& Sanna, 2016).

\section{Categoria 2- Necessidade de atualização dos atos profissionais na saúde mental}

Esta categoria trata da necessidade de atualização do processo de trabalho da enfermagem percebido pelas falas dos entrevistados. Quando questionados se tiveram necessidade de procurar outras formas para se aprofundar e compreender sobre o novo perfil e trabalho da enfermagem neste novo contexto da saúde mental, todos os entrevistados responderam que sim. As formas de atualização variaram desde leitura de livros e artigos, filmes, trocas de experiências com os demais membros da equipe multiprofissional e em cursos de especializações ainda em andamento, conforme vemos nas falas abaixo:

"Sim, através de estudos pela internet e livros. Estou fazendo uma pós-graduação em Saúde Mental e Atenção Psicossocial, com o objetivo de conhecer melhor a área da saúde mental e inserir no meu serviço." (E1, 2020)

"Sim. Leituras, trabalho em equipe, troca de experiências com outros profissionais.” (E2,2020)

"A graduação oferta um conhecimento generalista e para atuar na saúde mental é necessário "mergulhar" nos aspectos sociais, psíquicos, clínicos e sentimental de um indivíduo e família que vivencia o transtorno mental." $(E 3,2020)$

"Sim. Compreendo que o cuidado está sempre em construção, assim a sala de aula não consegue sanar toda a demanda de conhecimentos. Busquei em leituras de artigos, livros da área, filmes e documentários a compreensão dessa temática.” $(E 4,2020)$

"A graduação me ofereceu a base. Mas foi e será necessário novas atualizações para que eu possa significar melhor a minha atuação na saúde mental" (E6,2020)

"Sim, estudo, leitura de livros artigos leis, troca de experiência com outros profissionais (principalmente psicólogo e assistente social)." (E8,2020) 
Segundo a lógica da teoria bourdieusiana, o currículo da enfermagem na graduação é marcado por sistemas simbólicos, que estabelecem ideias e crenças sobre a legitimidade de quem produz o discurso. Desta maneira, o currículo é o campo social utilizado para produção de conhecimentos e onde diferentes atores e detentores de capital social legitimam as concepções por meio de lutas simbólicas para se obter a autoridade e o domínio do campo. Percebemos, portanto, que a base curricular delineia a noção de identidade e as práticas profissionais. No caso da enfermagem, seu currículo possui grande influência do modelo de atenção à saúde flexneriano, isolando e segmentando o corpo dos contextos políticos e sociais e definindo como etiologia do adoecimento apenas os fatores biológicos (Bourdieu, 1989; Carneiro \& Porto, 2014).

Diante a isso, os enfermeiros inseridos atualmente nos serviços de atendimentos de saúde mental, reconhecem a necessidade de repensar e aperfeiçoar seus conhecimentos técnicos e científicos, atualizando seu habitus e transformando seus atos profissionais a fim de implementarem um cuidado amplo frente ao novo panorama da saúde mental. O campo de conhecimento em saúde mental incorpora uma pluralidade de saberes e requer uma versatilidade do profissional, para que consiga responder da melhor maneira as necessidades dos usuários, com uma assistência que contemple os aspectos sociais, culturais, ambientais e psicológicos (Fortes et al., 2017; Marcolino, Fantinatti \& Gozzi, 2018).

No tocante a regulamentação das atribuições da enfermagem na Saúde Mental, no ano de 2018 o Conselho Federal de Enfermagem (COFEN) elaborou a norma técnica 599, instrumento importante que norteia e respalda o trabalho da enfermagem no campo da saúde mental com a finalidade de subsidiar uma assistência de qualidade e eficaz. Entre as competências da enfermagem definidas pela norma, estão desde os cuidados da vida diária, como também o dever de ajudar no desenvolvimento, no resgate da autonomia e autoestima destas pessoas. Através das abordagens terapêuticas empregadas nos CAPS, o enfermeiro deve estreitar os laços com os participantes, identificar suas vulnerabilidades, promover espaços de tolerância, buscando o bem-estar do sujeito e seu retorno para a convivência social (Cofen, 2018).

A compreensão de que as novas maneiras de avaliar e intervir em saúde mental estão sendo adquiridas durante a convivência da prática diária também foi levantado por um dos participantes:

"Estou passando pelo processo de identificação com base na minha prática diária e também na especialização que estou cursando" (E3,2020)

O cenário de prática se constitui como um importante recurso de produção de conhecimentos, desmistificando mitos e pré-conceitos. É um espaço de escuta e troca, sem a imposição de saberes hierarquizados e verdades absolutas por parte dos profissionais, mas um lugar de compartilhamento de saberes e experiências. No campo prático é possível desfazer a concepção estereotipada da loucura e de que os usuários nestas condições são submissos e subordinados. Abre-se mão da prática verticalizada e impositiva, e ocorre o aprendizado mútuo tanto com o usuário quanto com a equipe multiprofissional, reforçando a corresponsabilização do cuidado.

Novamente correlacionando com Bourdieu (1989), percebemos a relação de Poder Simbólico que envolve o enfermeiro sob o paciente. Nesta nova terapêutica, deve-se dissolver a ideia por parte destes profissionais de que são detentores de conhecimentos específicos e por isso são os responsáveis pela total tomada de decisão com relação ao cuidado dos usuários restringindo a autonomia destas pessoas. Com a proposta da reforma, estes indivíduos agora são sujeito-ativos em seu tratamento detentores de direitos e de voz ativa em seu tratamento (Maftum et al., 2017).

A crítica a respeito da ausência de capacitação ofertada pelo serviço também aparece conforme discurso a seguir:

“A graduação apenas apontou caminhos, assumir o novo perfil necessário é algo que tenho buscado aos poucos uma vez que o serviço é precário e não oferta capacitação.” (E3,2020) 
A precarização e o sucateamento do sistema de saúde repercutem no trabalho dos enfermeiros e nas tentativas de consolidar uma práxis coerente com o preconizado pela reforma psiquiátrica. Como percebido na fala acima, a falta de estímulos e capacitações ofertadas pelos órgãos públicos fez com que o profissional tivesse que ter iniciativa para buscar com seus próprios recursos capacitações e aperfeiçoamentos para ser possível a transformação de sua prática de acordo com a atualidade. O campo da saúde mental necessita muito mais de recursos humanos capacitados para superar as práticas institucionalizadas e sustentar as novas ideologias do que de recursos materiais e tecnológicos. Sendo assim é fundamental que as gestões possibilitem capacitações com especialistas e novas metodologias de trabalho para os trabalhadores de forma contínua, prevenindo assim retrocessos no tratamento deste grupo vulnerável (Marcolino, Fantinatti \& Gozzi, 2018).

Uma das estratégias utilizadas pela gestão do município para aperfeiçoar os serviços de saúde e ao mesmo tempo atualizar os trabalhadores é a parceria com os programas de Residência Multiprofissional em Saúde ofertados pela Universidade Federal de Juiz de Fora.

“[...] Encontro Nacional da RAPS; mesas-redonda; grupo de trabalho de Enfermagem dos CAPS, no qual tivemos momentos de educação permanente, com a participação dos residentes da Residência Multiprofissional em Saúde Mental (UFJF); grupo de educação permanente com a equipe de Enfermagem no CAPS onde atuo, também com a participação dos residentes da Residência Multiprofissional em Saúde Mental (UFJF). “(E7,2020)

A Residência Multiprofissional em Saúde é uma modalidade de ensino de especialização lato sensu, voltada para a formação em serviço, criada em 2005 a partir da lei nº 11.129. Seu intuito é formar profissionais comprometidos para atuar na saúde pública do país e em concordância com os princípios e diretrizes do SUS. Trata-se de uma formação caracterizada pelo trabalho multidisciplinar, intersetorial, que possibilita que o residente adquira qualificação através da articulação com profissionais já inseridos na área, entre eles, o seu preceptor, profissional de sua categoria profissional, que através do processo de partilha de experiências e saberes ficará encarregado de lhe passar todo o passo a passo do cotidiano do serviço (Silva et al., 2016; Onocko-Campos, Emerich \& Ricci, 2019).

Os serviços substitutivos são campos de ensino e de pesquisa, e o programa de residência multiprofissional em saúde mental é importante instrumento para a qualificação e o fortalecimento da atenção psicossocial. Através de práticas multidisciplinares e com lógica interdisciplinar os residentes buscam compreender as multicausalidades do processo saúdedoença focando na integralidade, fomentando o pensamento crítico e reflexivo e assim superando as fragilidades da graduação. O programa atua também como estratégia de educação permanente, proporcionando atualização das concepções e atos dos profissionais de saúde já ativos, estimulando a transformação do cenário de prática e construindo novas formas de produzir saúde (Onocko-Campos, Emerich \& Ricci, 2019).

\section{Considerações Finais}

O intuito deste estudo foi identificar se o ensino da saúde mental na graduação dos enfermeiros permite que esta classe ressignifique seus saberes e práticas para uma atuação condizente com a proposta da nova política de saúde mental no país e refletir se os profissionais enfermeiros estão sendo formados para conseguirem se apropriar do seu papel e espaço nos serviços substitutivos, participando desta forma ativamente na efetivação da Reforma Psiquiátrica.

Observado pelas respostas que a lacuna entre a teoria com a prática no que tange a disciplina de saúde mental nas universidades ainda é presente. Mesmo após 20 anos da Lei 10.216, os enfermeiros continuam com dificuldades para reconhecer sua práxis dentro dos CAPS e reconhecem que os conteúdos adquiridos durante a sua formação não foram suficientes para um trabalho adequado dentro dos moldes da nova ideologia da saúde mental. Entretanto, mesmo com as 
disparidades da formação, os profissionais atuantes nos CAPS procuram se aperfeiçoar e modificar seu habitus profissional, desvinculando aos poucos das práticas conservadoras enraizadas pela formação e adquirindo novos saberes e condutas para a execução de um trabalho amplo, interdisciplinar e resolutivo.

Em suma, faltam estímulos e capacitações dos órgãos públicos para os trabalhadores deste campo o que acarreta na precariedade da assistência e desvalorização do campo. O Programa de Residência em Saúde Mental proposto pela universidade e funcionando em parceria com a prefeitura da cidade é visto como um importante instrumento de educação permanente para os trabalhadores ativos e também para a preparação de novos profissionais comprometidos com a Política Pública de Saúde, contudo é necessário mais investimento por parte das gestões públicas para capacitar os profissionais desta área e consolidar uma assistência humanizada e inclusiva.

Para que a nova Saúde mental seja efetivada e seus objetivos alcançados, são necessários estudos mais abrangentes sobre o processo de formação dos profissionais que irão atuar neste campo, não apenas dos profissionais enfermeiros como também das demais profissões do âmbito da saúde, desta maneira será possível para as instituições formadoras identificar as problemáticas e os desafios que os atuais modelos de ensino apresentam e criar métodos e estratégias que minimizem esta dicotomia existente entre teoria e prática reorientando o processo educativo destes futuros profissionais.

\section{Limitações do estudo}

O estudo aponta limitação referente à abrangência da coleta de dados, visto que devido a pandemia da COVID-19 foi utilizado o recurso do envio do instrumento semiestruturado por e-mail impedindo assim que os pesquisadores conseguissem aprofundar algumas respostas e assuntos abordados pelos participantes.

\section{Referências}

Bardin, L. (1977). Análise de Conteúdo. Editora Edições 70.

Baião J. J., \& Marcolan J. F. (2020). Labirintos da formação em enfermagem e a Política Nacional de Saúde Mental, Rev Bras Enferm [online]. 73(1). https://www.scielo.br/scielo.php?pid=S0034-71672020001300185\&script=sci_arttext\&tlng=pt\#: :text=No\%20que\%20tange\%20a\%20forma\%C3\%A7\%C3 $\% \mathrm{~A} 3 \mathrm{o}$, as $\% 20 \mathrm{pr} \% \mathrm{C} 3 \% \mathrm{~A} 1$ ticas $\% 20$ desses $\% 20$ futuros\%20profissionais.

Borges, C. A. S., Vasconcelos, C. R.; Oselame, G. B., \& Dutra, D. A. (2016). O novo perfil profissional do enfermeiro frente ao centro de atenção psicossocial. Revista de Medicina e Saúde de Brasília, 5(2), 217-233. https://portalrevistas.ucb.br/index.php/rmsbr/article/download/7162/4566.

Bourdieu, P. (1989). O Poder Simbólico. Editora Bertrand Brasil S.A.

Bossato H. R., Oliveira R. M. P., Dutra, V. F. D., \& Loyola C. M. D. (2021). A enfermagem e o protagonismo do usuário no CAPS: um estudo na perspectiva construcionista. Revista Gaúcha Enfermagem [online], (42). https://www.scielo.br/scielo.php?pid=S1983-14472021000200401\&script=sci_arttext\&tlng=pt

Brasil. Ministério da Saúde. (2015). Centros de Atenção Psicossocial e Unidades de Acolhimento como lugares da atenção psicossocial nos territórios: orientações para elaboração de projetos de construção, reforma e ampliação de CAPS e de UA, (1), 1-46. http://bvsms.saude.gov.br/bvs/publicacoes/centros_atencao_psicossocial_unidades_acolhimento.pdf

Câmara, R. H. (2013). Análise de conteúdo: da teoria à prática em pesquisas sociais aplicadas às organizações. Revista Interinstitucional de Psicologia, 6(2), 179-191. http://pepsic.bvsalud.org/scielo.php?script=sci_arttext\&pid=S1983-82202013000200003\&lng=pt\&nrm=iso\&tlng=pt.

Caregnato, R. C. A., \& Mutti R. (2006). Pesquisa qualitativa: análise de discurso versus análise de conteúdo. Revista Texto Contexto Enfermagem 15(4,) 67984. https://www.scielo.br/scielo.php?pid=s0104-07072006000400017\&script=sci_abstract\&tlng=pt.

Carneiro, L. A., \& Porto, C. C. (2014). Saúde mental nos cursos de graduação: interfaces com as diretrizes curriculares nacionais e com a reforma psiquiátrica. Cadernos Brasileiros de Saúde Mental, 6(14), 150-167. https://periodicos.ufsc.br/index.php/cbsm/article/view/68544\#: : text=As\%20Diretrizes\%20Curriculares\%20Nacionais\%20para,de\%20servi\%C3\%A7os\%20abertos\%20e\%20comunit\%C3\%A1rios.

Coelho, V. A. A., Volpe, F. M., Diniz, S. S. L., Silva, E. M., \& Cunha, C. F. (2014). Alteração do perfil de atendimento dos hospitais psiquiátricos públicos de Belo Horizonte, Brasil, no contexto da reforma da assistência à saúde mental. Revista Ciência Saúde coletiva [online], 19(8), 3605-3616. https://www.scielo.br/scielo.php?pid=S1413-81232014000803605\&script=sci_abstract\&tlng=pt.

Conselho Federal de Enfermagem, Brasil. (2018), "RESOLUÇÃO COFEN No 0599/2018. http://www.cofen.gov.br/resolucao-cofen-no-5992018_67820.html. 
Cortes, J. M., Kantorski, L. P., Barros, S., Antonacci, M. H., Chiavagatti, F. G., \& Willrich, J. Q. (2014). Saberes e fazeres que integram o ensino de enfermagem psiquiátrica na perspectiva de enfermeiros docentes. Revista Portuguesa de Enfermagem de Saúde Mental, (12), 34-42. http://www.scielo.mec.pt/scielo.php?script=sci_arttext\&pid=S1647-21602014000300005\&lng=pt\&tlng=pt.

Duarte, V. F., Neto, G. L., Rodrigues, L., \& Campos, C. J. G. (2016). Ditos acadêmicos do ontem e do hoje acerca do papel da enfermagem no processo e rotina da desinstitucionalização. SMAD. Revista eletrônica saúde mental álcool e drogas, 12(2), 116-136. http://pepsic.bvsalud.org/scielo.php?script=sci_arttext\&pid=S1806-69762016000200008\&lng=pt\&nrm=iso\&tlng=pt

Esperidião, E., Silva, N. S., Caixeta, C. C., \& Rodrigues, J. (2013). A Enfermagem Psiquiátrica, a ABEN e o Departamento Científico de Enfermagem Psiquiátrica e Saúde Mental: avanços e desafios. Rev. bras. Enferm, (66), 171-176. https://www.scielo.br/scielo.php?script=sci_arttext\&pid=S003471672013000700022

Fortes, F. L. S., Peres, M. A. A; Santos, T. C. F; Martins, G. C. S., Montenegro, H. R. A., \& Almeida Filho, A. J. (2017). Enfermeiro em saúde mental: concepções sobre qualificação profissional em um Centro de Atenção Psicossocial. Rev Rene, 18(6), 763-70. http://periodicos.ufc.br/rene/article/view/3 1086\#: :text=Objetivo\%3A\%20analisar\%20as\%20estrat\%C3\%A9gias\%20adotadas,ao\%20Centro\%20de\%20Aten\%C3\%A7\%C3\%A3o\%20Psicossocial.

Fortes, F. L. S. (2017). Tese (Doutorado em Enfermagem): Atuação do enfermeiro na implantação do primeiro centro de atenção psicossocial no município de juiz de fora - mg (1994-2002). Biblioteca Virtual em Saúde. https://pesquisa.bvsalud.org/portal/resource/pt/biblio-836775

Gil, A. C. (2002). Como Elaborar Projetos de Pesquisa. Editora Atlas.

Hertel, V. L. (2019). Práticas pedagógicas na formação profissional do enfermeiro: o processo de ensino do cuidar em enfermagem. Saúde e Biociência, 2 (1), 1-18. http://publicacoes.unifatea.edu.br/index.php/saudebiociencias/article/view/1391

Lima, I. C. B. F., \& Passos, I. C. F. (2019). Residências integradas em saúde mental: para além do tecnicismo. Trabalho, Educação e Saúde, 17(2), 1-22. https://www.scielo.br/scielo.php?script=sci_arttext\&pid=S1981-77462019000200512

Lopes, M. E. L., Sobrinho, M. D., \& Costa, S. F. G. (2013). Contribuições da sociologia de Bourdieu para o estudo do Subcampo da enfermagem. Texto Contexto Enferm, 22(3), 819-25. https://www.scielo.br/scielo.php?script=sci_arttext\&pid=S0104-07072013000300031\#: :text=O\%20estudo\%20possibilito u\%2 C\%20a\%20partir,pelos\%20enfermeiros\%20no\%20campo\%20da

Luz, V. L. E. S., Barjud, A. C. P., Moura, A. S., Sales, J. C. S., Coelho, D. M. M., \& Duarte, M. R. (2014). Ações realizadas pelo enfermeiro em Centros de Atenção Psicossocial. R. Interd, 7(4),1-12. https://revistainterdisciplinar.uninovafapi.edu.br/index.php/revinter/article/view/368

Marcolino, T. Q., Fantinatti, E. M., \& Gozzi, A. P. N. F. (2018). Comunidade de prática e cuidado em saúde mental: uma revisão sistemática. Trab. Educ. Saúde, 16 (2), 643-658. https://www.scielo.br/scielo.php?script=sci_arttext\&pid=S1981-77462018000200643

Maftum, M. A., Pagliace, A. G. S., Borba, L. O; Brusamarello, T., \& Czarnobay, J. (2017). Mudanças ocorridas na prática profissional na área da saúde mental frente à reforma psiquiátrica brasileira na visão da equipe de Enfermagem. Rev Fund Care online, 9(2), 309-314. http://www.seer.unirio.br/index.php/cuidadofundamental/article/view/3626.

Minayo, M. C. S. (2002). Pesquisa Social: Teoria, método e criatividade. Editora Vozes.

Muniz, M., Tavares, C., Abrahão, A., \& Souza, A. (2015). A Assistência de Enfermagem em Tempos de Reforma Psiquiátrica. Revista Portuguesa de Enfermagem de Saúde Mental, (13), 61-65. http://www.scielo.mec.pt/scielo.php?script=sci_arttext\&pid=S1647-21602015000200008.

Neves V. R., \& Sanna M. C. (2016). Conceitos e práticas de ensino e exercício da liderança em Enfermagem. Rev. Bras. Enferm. [Internet], 69(4), 686-93. https://www.scielo.br/scielo.php?script=sci_arttext\&pid=S0034-71672016000400733

Nunes, V. V., Feitosa, L. G. G. C., Fernandes, M. A., \& Ramos, C. V. (2020). Saúde mental na atenção básica: atuação do enfermeiro na rede de atenção psicossocial. Rev Bras Enferm (online), 73(1). https://www.scielo.br/scielo.php?script=sci_abstract\&pid=S003471672020001300161\& lng=pt\&nrm=iso\&tlng=pt.

Onocko-Campos R., Emerich B. F., \& Ricci E. C. (2019). Residência Multiprofissional em Saúde Mental: suporte teórico para o percurso formativo. Interface (23). https://www.scielo.br/scielo.php?script=sci_abstract\&pid=S1414-32832019000100504\&lng=en\&nrm=iso\&tlng=pt

Pereira, A. S., Shitsuka, D. M., Pereira, F.J., \& Shitsuka R. (2018). Metodologia da pesquisa científica [recurso eletrônico]. Santa Maria UAB/NTE/UFSM. https://repositorio.ufsm.br/bitstream/handle/1/15824/Lic_Computacao_Metodologia-Pesquisa-Cientifica.pdf?sequence=1.

Rodrigues J., Kempfer S. S., Lenz J. R., \& Oliveira S. N. (2017). Influência das reformas curriculares no ensino de saúde mental em enfermagem: 1969 a 2014. Rev Gaúcha Enferm [online], 38(3). https://www.scielo.br/scielo.php?script=sci_arttext\&pid=S1983-14472017000300407\#: :text=A\%20influ\%C3\%A An cia\%20das\%20modifica\%C3\%A7\%C3\%B5es\%20curriculares,pela\%20Reforma\%20Curricular\%20e\%20Psiqui\%C3\%A1trica.

Santos, J., Lino, D., Vasconcellos, E., \& Souza, R. (2016). Processos formativos da docência em saúde mental nas graduações de enfermagem e medicina. Revista Portuguesa de Enfermagem de Saúde Mental, (4), 85-92. http://www.scielo.mec.pt/scielo.php?script=sci_abstract\&pid=S1647$21602016000400013 \& \operatorname{lng}=\mathrm{pt} \& \mathrm{nrm}=\mathrm{iso}$

Silva, E. A., \& Costa, I. I. (2010). O profissional de referência em Saúde Mental: das responsabilizações ao sofrimento psíquico. Revista Latinoamericana de Psicopatologia Fundamental, 13(4), 635-647. https://www.scielo.br/scielo.php?script=sci_arttext\&pid=S1415-47142010000400007

Silva, C. T., Terra, M. G., Kruse, M. H. L., Camponagara, S., \& Xavier, M. S. (2016). Residência multiprofissional como espaço intercessor para a educação permanente em saúde. Texto Contexto Enferm, 2016; 25(1). https://www.scielo.br/scielo.php?pid=S0104-07072016000100304\&script=sci_abstract\&tlng=pt

Silva, S. M., Machado, P. A. T., Nascimento, R. S., Oliveira, T. S., Silva, T. F., \& Batista, E. C. (2017). A enfermagem no campo da saúde mental: uma breve discussão teórica. Revista Amazônia Science, 5(2), 40-46. http://ojs.unirg.edu.br/index.php/2/article/view/1393 
Research, Society and Development, v. 10, n. 2, e33610212634, 2021

(CC BY 4.0) | ISSN 2525-3409 | DOI: http://dx.doi.org/10.33448/rsd-v10i2.12634

Souza, M. C., \& Afonso, M. L. M. (2015). Saberes e práticas de enfermeiros na saúde mental: desafios diante da Reforma Psiquiátrica. Gerais, Rev. Interinst. Psicol. [online], 8(2), 332-347. http://pepsic.bvsalud.org/scielo.php?script=sci_abstract\&pid=S1983-82202015000300004\&lng=pt\&nrm=iso

Souza D. F., \& Silvino Z. R. (2018). A Sociologia de Pierre Bourdieu: potencialidade teórica para o subcampo da enfermagem. Revista Brasileira Enfermagem [Internet]. 71(4). https://www.scielo.br/pdf/reben/v71n4/pt_0034-7167-reben-71-04-2055.pdf

Tavares, C., Gama, L., Souza, M. T., Paiva, L., Silveira, P., \& Mattos, M. (2016). Competências Específicas do Enfermeiro de Saúde Mental Enfatizadas no Ensino de Graduação em Enfermagem. Revista Portuguesa de Enfermagem de Saúde Mental, (4), 25-32. http://www.scielo.mec.pt/scielo.php?script=sci_arttext\&pid=S1647-21602016000400004.

Teixeira, M. O. L. (2019). Pinel e o nascimento do Alienismo. Estudos e Pesquisas em Psicologia, 19(2), 540-560. http://pepsic.bvsalud.org/scielo .php?script=sci_arttext\&pid=S1808-42812019000200012

Vargas, D., Maciel, M. E. D., Bittencourt, M. N., Lenate, J. S., \& Pereira, C. F. (2018). O ensino de enfermagem pisiquiátrica e saúde mental no brasil: análise curricular da graduação. Revista Texto \& Contexto - Enfermagem, 27(2). https://www.scielo.br/scielo.php?pid=S0104-07072018000200316\& script=sci_abstract\&tlng=pt 